\title{
Lymphoplasmacyte rich meningioma: A rare variant of meningioma mimicking diffuse granulomatous disease with leptomeningeal spread
}

\author{
Damber Bikram Shah $M S^{1}$, Prasanna Karki $P h D^{2}$, Prakash Paudel $F C P S^{3}$, Sumit Joshi $M S^{4}$, Prabhaw Upadhhya \\ $M D^{5}$, Gopal Raman Sharma $M S^{6}$ \\ ${ }^{1,2,3,4,6,7}$ Department of Neurosciences, Nepal Mediciti Hospital, Sainbu, Lalitpur, Nepal, ${ }^{5}$ Neurology, Department of \\ Neuroscience, Nepal Mediciti Hospital, Lalitpur, Nepal
}

Date of submission: $16^{\text {th }}$ August 2020

Date of acceptance: $13^{\text {th }}$ November 2020

Date of publication: $1^{\text {st }}$ December 2020

\begin{abstract}
Lymphoplasmacyte-rich meningioma is a rare variant of World Health Organization (WHO) Grade I meningioma, which may present as diffuse granulomatous disease with leptomeningeal spread. Here, we report a case of 61 years old man who presented with gradual onset of progressive quadriperesis. Patient was initially treated with antitubercular medications as imaging studies and serum markers were suggestive of granulomatous lesion. Surgical intervention was adviced as patient did not respond to medical management. Histopathology and immunohistochemistry confirmed the diagnosis of lymphoplasmacyte-rich meningioma. This meningioma can present as diffuse leptomeningeal infiltrative lesion involving both the hemispheres and all the tentorial surfaces mimicking inflammatory lesion. Tuberculosis is very common in our part and the diffuse infiltrative nature of lymphoplasmacyte-rich meningioma with similar radiological features of these two pathologies may confuse and delay the diagnosis. Recognition of this entity is of utmost importance as it guides proper management.
\end{abstract}

Key words: meningioma, lymphoplasmacyte rich meningioma, granulomatous disease

Access this article online
Website: https://www.nepjol.info/index.php/NJN
DOI: https://doi.org/10.3126/njn.v17i3.33123
HOW TO CITE
Shah DB, Karki P, Paudel P, Joshi S, Upadhhya P, Aryal G,
Sharma GR. Lymphoplasmacyte rich meningioma: a rare variant
of meningioma mimicking diffuse granulomatous disease with
leptomeningeal spread. NJNS. 2020;17(3):36-40

'ORCID id: 0000-0002-5707-7696

2ORCID id: 0000-0003-1469-3517

${ }^{3}$ ORCID id: 0000-0002-8830-3908

${ }^{4}$ ORCID id: 0000-0002-7883-9354

${ }^{5}$ ORCID id: 0000-0002-3173-6243

${ }^{6}$ ORCID id: 0000-0003-3638-4993

Address for correspondence:

Dr Damber Bikram Shah

Department of Neurosciences,

Nepal Mediciti, Hospital,

Sainbu, Lalitpur, Nepal

PO Box 44600

Phone: +977-9841765533

E-mail: drdbshah01@gmail.com

Copyright (C) 2020 Nepalese Society of Neurosurgeons (NESON)

ISSN: 1813-1948 (Print), 1813-1956 (Online)

\section{Introduction}

$\mathrm{M}$ eningiomas are divided into three grades and $15 \mathrm{sub}$ types according to the 2007 WHO classification of tumors ofCNS. ${ }^{1,2}$ Lymphoplasmacyte Meningioma (LPM) was first reported by Banerjee and Blackwood in 1971. ${ }^{3,4}$ It is a Grade I subtype of intracranial meningiomas which has been adapted to the WHO classification since 1993, LPM is characterized by exuberant lymphoplasmacytic inflammatory cell infiltrate and is one of the rarest variants of meningioma. Lymphoplasmacytic meningiomas occur most commonly over cerebral convexities. Other sites include sphenoid ridges, olfactory grooves, parasellar regions, petrous ridges, tentorium and posterior fossa. ${ }^{5}$ Because of its atypical histology and clinical presentation, some investigators have argued against diagnosis of this particular type of tumor as a meningioma. ${ }^{6,7}$ Meningiomas presenting as tumors with the features of a LPM are very unusual. ${ }^{8-12}$ The pathophysiology associated with this form of tumor is poorly understood. We report a case of LPM in a 61 years old male patient, surgical resection of the lesion was performed and the histopathological diagnosis was made. 


\section{Case report}

A 61 years old male presented with gradual onset weakness of bilateral upper and lower limbs. Initially the weakness started from right lower limb then gradually progressed to involve all the four limbs over the period of 3 months. The weakness was associated with paresthesia with inability to perform his daily activities on his own with Modified Rankin Scale (MRS) of 4. His upper limb power was right $2 / 5$, left $3 / 5$ and lower limb bilateral $3 / 5$ according to Medical Research Council (MRC) power grading system. He was a known case of hypertension for 30 years and Type 2 Diabetes Mellitus for 10 years under medication. Nerve conduction studies ruled out neuropathy. Lumbar puncture was done which showed lymphocyte predominance and high protein levels. Therefore, a provisional diagnosis of tuberculosis was made and patient was started on Anti Tubercular Therapy (ATT) along with steroid. However, no clinical improvements were seen and repeat CSF examinations showed no significant findings. The MRI brain showed T2 and FLAIR high signal in bilateral frontal lobes (Figure 1.A, 1.B) and post contrast MRI showed patchy enhancing homogenous plastering lesion along the skull base meninges, falx cerebrii, tentorium and encasing bilateral carotid arteries (Figure. 1C, 1.D, 1.E, 1.F). However, there was no edema surrounding the lesion.
The tissue biopsy was carried out from suprasellar area extending to the skull base and dural surface including medulla. Grossly the lesion was highly vascular, pinkish, diffuse, plastered to the surface with abnormal tissue attached to the dura and pial surface involving the optic nerve as well as carotid artery (arrow) (Figure 2A). The lesion was dissected meticulously from brain surface using dissector (arrow) (Figure 2B, 2C) and part of it was cut with micro-scissor for biopsy (arrow) (Figure 2D).

The Hematoxylin Staining (H.E) x200 (Figure 3A) showed scattered small clusters of menin- gothelial cells with characteristic whorling and indistinct cells outlines on a fibrous stroma. Prominent lymphoplasmacytic infiltrate is seen with lymphoid aggregates, increased vascularity and sheets of histiocytes. The histopathology showed lymphoplasmacytic-rich (inflammation-rich) meningioma, WHO Grade I (Figure 3). The diagnosis was further confirmed by IHC where the tumor cells were positive for vimentin (Figure 3B), EMA (Figure 3C), PR (Figure 3D), CD20 (Figure 3E), Ki67 (Figure 3F), CD138 (Figure 3G), CD68 (Figure 3H) and negative for GFAP (Figure 3I).

In our case the lesion was diffuse infiltrative and surgically inaccessible for total resection. Radiotherapy was suggested after biopsy.
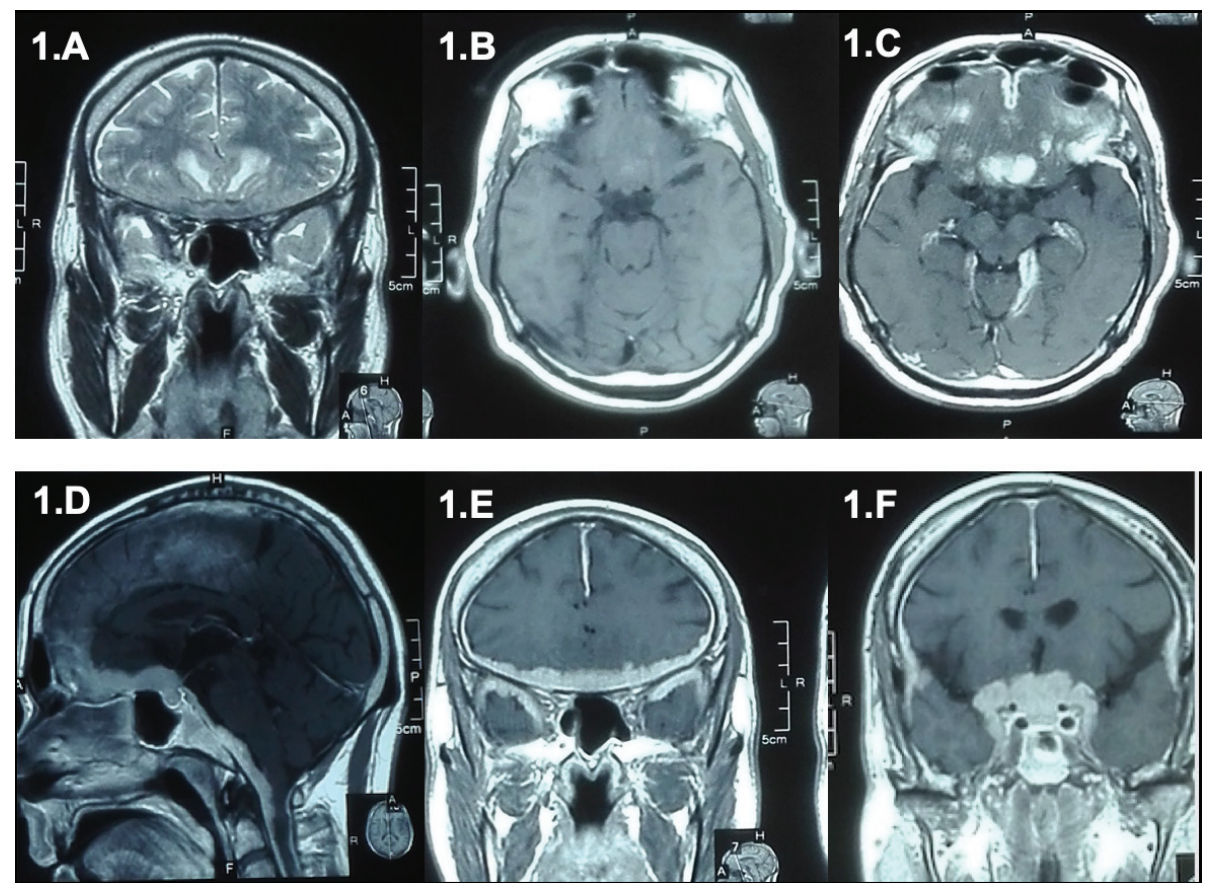

Figure 1A: The T2 Weighted Coronal brain MRI showing bilateral frontal lobe signal changes. 1.B. The Axial Fluidattenuated inversion recovery (FLAIR) image showing bilateral frontal lobe hyperintensity patches. 1.C, D, E, and F. The post Gadolinium contrast MRI showing patchy enhancement of adjacent meninges along skull base, tentorium, diffuse homogenous enhancing supresellar lesion extending to skull base and dural surface including medulla, base of bifrontal lobe, along the falx cerebrii and superior to bitemporal region and encasement of bilateral carotid artery. 
Shah et al
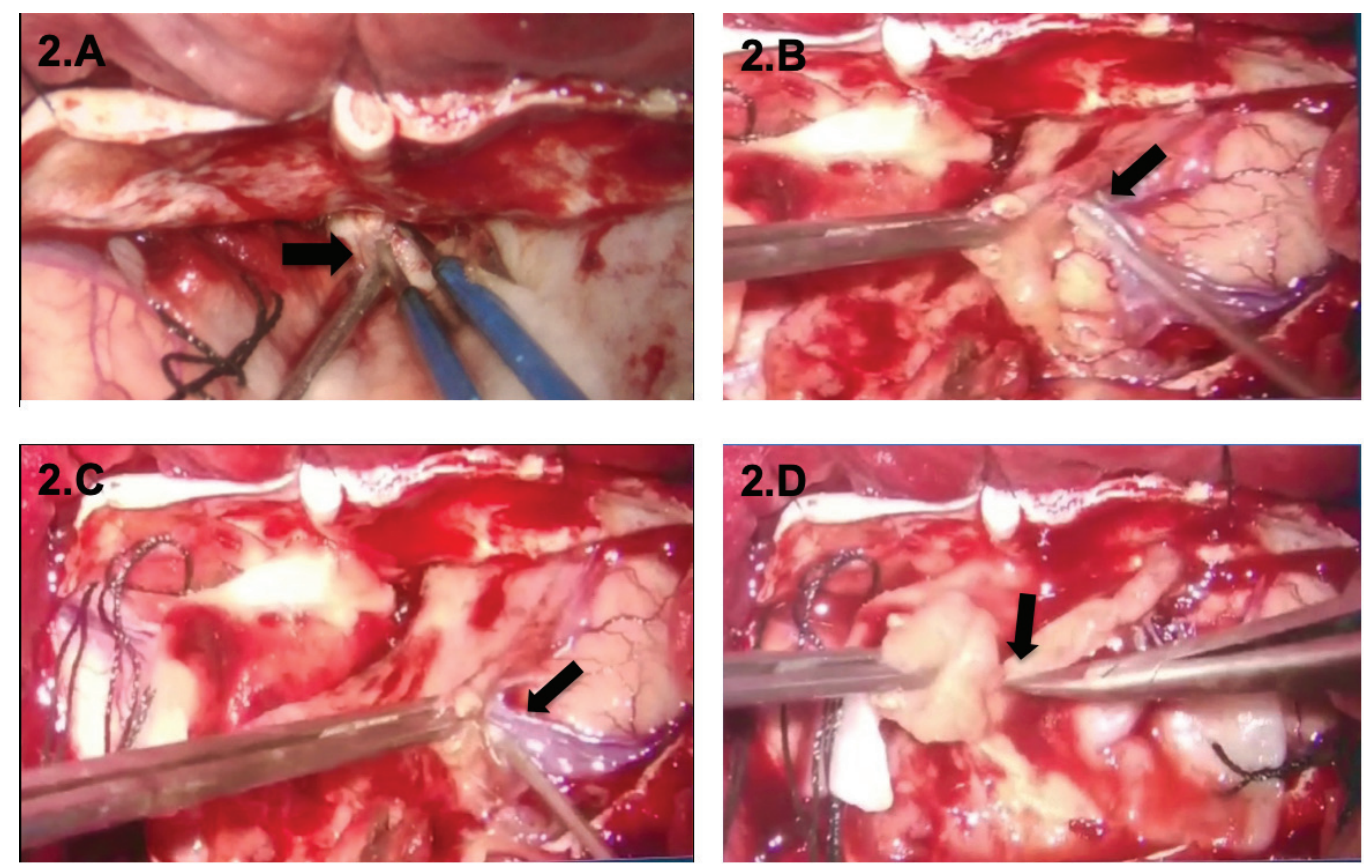

Figure 2A: The arrow showing grossly highly vascular, pinkish white lesion intraoperatively. B. The arrow showing plastered lesion over pial surface of brain being dissected intraoperatively. C. The arrow showing plastered lesion over pial surface and its dissection along with vessels intraoperatively. D. The arrow showing biopsy of the lesion being taken intraoperatively.
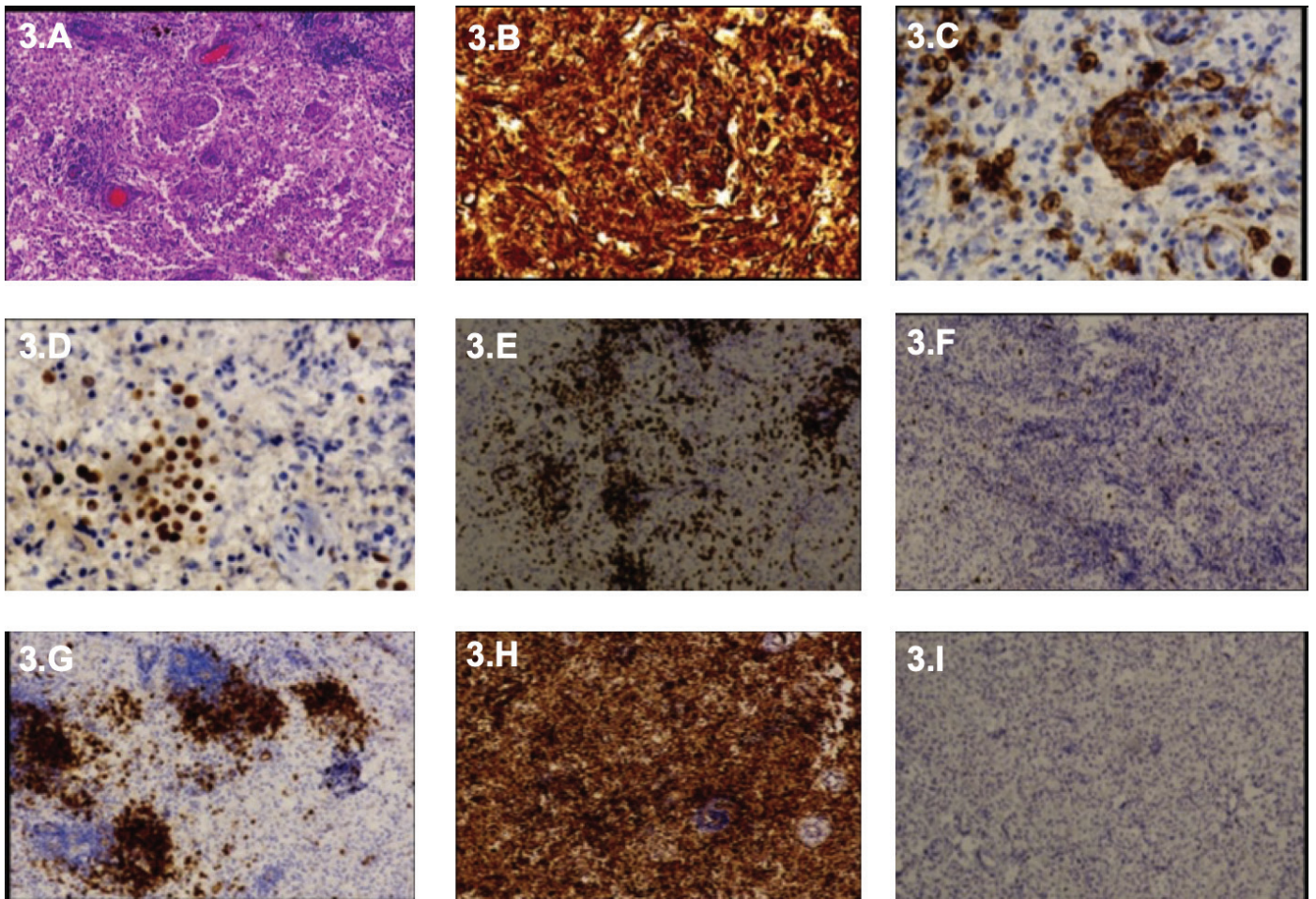

Figure 3A: The Hematoxylin Staining (H.E) x200 showing scattered small clusters of menin- gothelial cells with characteristic whorling and indistinct cells outlines on a fibrous stroma. Prominent lymphoplasmacytic infiltrate is seen with lymphoid aggregates, increased vascularity and sheets of histiocytes. $B, C, D, E, F$, $G$, H: The Immunoshistochemistry (IHC) Study showing positive for vimentin (V9), Epithelial membrane antigen (EMA), progesterone receptor (PR), CD20 staining B cells, Ki67, CD138 and CD68. I. The Immunohistochemistry (IHC) study showing negative for Glial fibrillary acidic protein (GFAP). 


\section{Discussion}

Meningiomas are the most common primary CNS tumors and accounts for approximately one-third of all primary brain and spinal tumors. ${ }^{3,4}$ Meningiomas are divided into 3 grades and 15 sub-types according to the 2007 WHO classification of tumors of central nervous system (CNS). ${ }^{1,2}$ LPM is a rare WHO Grade I subtype of meningioma. ${ }^{3}$

LPM, was first reported by Banerjee and Blackwood in $1971 .{ }^{4}$ It has been adapted to the WHO classification since 1993. The patients with LPM have variable clinical manifestations according to the location of the tumor. The common presentations include headache, hemiparesis, seizure, vomiting, dizziness, visualdisturbance, dyscalculia, dysgraphia and slurred speech. ${ }^{15}$ LPM is characterized by exuberant lymphoplasmacytic inflammatory cell infiltrate. It occurs most commonly over cerebral convexities. Other sites include sphenoid ridges, olfactory grooves, parasellar regions, petrous ridges, tentorium and posterior fossa. ${ }^{5}$ In the new WHO classification of tumors of the meninges, 8 lymphoplasmacyte-rich meningioma, is characterized by the dense infiltration of lymphocytes and plasma cells. Banerjee and Blackwood ${ }^{4}$ regarded it as a collision tumor with ordinary meningioma and plasmacytoma components. On the other hand, Russell and Rubinstein ${ }^{8}$ expressed the opinion that the infiltration of plasma cells was of a secondary character rather than that of collision tumors.

Actually, the origin (neoplastic or inflammatory) of this tumor is unclear; its biological behavior and clinical course are anomalous so it is considered closer to intracranial inflammatory masses rather than typical meningioma. ${ }^{12}$ Like in our case the LPM does not have typical imaging features of a meningioma so it can mimic intracranial inflammatory condition or brain neoplasm. Intracranial plasma cell granulomas ${ }^{13,14}$ and dural plasmacytoma $^{15,16}$ are often confused with meningiomas at the radiographic level. Moreover, inflammatory pseudo tumors, inflammatory fibrous histiocytomas, lymphomatoid granulomatosis and sinus histiocytosis with massive lymphadenopathy are also considered in the differential diagnosis. ${ }^{17}$ The tumor exhibits a positive immune-expression for EMA in a membranous pattern, a diffuse immunoreactivity for vimentin, which are similar to our case IHC findings. ${ }^{18,19}$

Total excision is the treatment of choice in LMP but in our case we could only do biopsy of the lesion due to its unusual pattern. As the lesion was diffuse, infiltrative and surgically inaccessible radiotherapy was suggested after biopsy. It is reported that in complex skull base meningiomas, a high tumour control rate in the range of $85-100 \%$ at 5 years with a low risk of significant incidence of long-term toxicity after radiotherapy. ${ }^{20}$

Our case had initial clinical and laboratory diagnosis of tubercular meningitis but on further investigations like histopathology and immunohistochemistry, we could come out with final diagnosis of LPM. LPM is rare and usually associated with a favorable outcome. Surgical resection is the treatment of choice. However, whether this entity has an inflammatory origin or a neoplastic one is still uncertain and requires research on the subject. ${ }^{13}$

\section{Conclusion}

Lymphoplasmacyte -rich meningioma is rare and usually associated with a favourable outcome. However, it can be confused with inflammatory lesion which delays the proper treatment. Hence, recognition of this entity is of utmost importance as it guides proper management.

Conflict of Interest: None

Source(s) of support: None

\section{References}

1. Wiemels J, Wrensch M, Claus EB. Epidemiology and etiology of meningioma. $\mathrm{J}$ Neurooncol 2010;99(3):307-14. https://doi.org/10.1007/s11060010-0386-3.

2. Ostrom QT, Gittleman H, Farah P, et al. CBTRUS statistical report: Primary brain and central nervous system tumors diagnosed in the United States in 2006-2010 [published correction appears in Neuro Oncol. 2014 May;16(5):760]. Neuro Oncol. 2013;15 Suppl 2(Suppl 2):ii1-ii56. https://doi.org/10.1093/ neuonc/not 151

3. Scheithauer, B.W. Tumors of the meninges: proposed modifications of the World Health Organization classification. Acta Neuropathol 80, 343-354 (1990). https://doi.org/10.1007/BF00307686

4. Banerjee AK, Blackwood W. A subfrontal tumour with the features of plasmocytoma and meningioma. Acta Neuropathol. 1971;18(1):84-88. https://doi. org/10.1007/BF00684477

5. Cambruzzi E, Thaís Amara da Costa de S; Silveira LC; Moreira C, dos Santos F. Lymphoplasmacyterich meningioma: a case report of a rare neoplasm. Jornal Brasileiro de Patologia e Medicina Laboratorial 2012;48(3): 223-227. https://doi.org/10.1590/S167624442012000300012 


\section{Shah et al}

6. Cannella DM, Prezyna AP, Kapp JP. Primary intracranial plasma-cell granuloma. Case report. J Neurosurg. 1988;69(5):785-788. https://doi. org/10.3171/jns.1988.69.5.0785

7. Yamaki $\mathrm{T}$, Ikeda $\mathrm{T}$, Sakamoto $\mathrm{Y}$, et al. Lymphoplasmacyterich meningioma with clinical resemblance to inflammatory pseudotumor. Report of two cases. J Neurosurg 1997;86:898-904. https://doi. org/10.3171/jns.1997.86.5.0898

8. Russell DS, Rubinstein LJ. Pathology of Tumors of the Nervous System, 5th edition. London: Edward Arnold, 1989;472. https://doi.org//10.1002/ path.1711580413

9. Horten BC, Urich H, Stefoski D. Meningiomas with conspicuous plasma cell-lymphocytic components: a report offive cases. Cancer 1979;43(1):258-64.https:// doi.org/10.1002/1097-0142(197901)43:1<258::aidcncr2820430137>3.0.co;2-9.

10. Loiseau H, Pedespan JM, Vital A, et al. Lymphoplasmacyterich meningioma in a child. Case report. J Neurosurg 1995;83:1075-9. https://doi. org/10.3171/jns.1995.83.6.1075

11. Bruce C, Horten MD, Henry Urich MD. Meningioma with conspicuous plasma celllymphocytic components. A report of five cases. Cancer 1979;43:1:258-264. https://doi. org/10.1002/1097-0142(197901)43:1<258::AIDCNCR2820430137>3.0.CO;2-9

12. Bruno MC, Ginguen C, Santangelo M, Panagiotopoulos K, Piscopo GA, Tortora F et al lymphoplasmacyte rich meningioma. A case report and review of the literature. J Neurosurg Sci 2004 Sep;48(3):117-24. PMID: 15557881
13. Kashyap A, Mukherjee T, Chauhan RD. Lymphoplasmacyte -rich meningioma $-\mathrm{A}$ rare case report and review of literature. World Jour of Surg Med and Rad Onco 2017,6:4.

14. Mizushima M, Tanaka Y, Kawakami S, Hori T, Ohama E. Lymphoplasmacyte-rich meningioma: a case report with histological and immunohistochemical studies. Brain Tumor Pathol. 1997;14(1):59-62. https://doi.org/10.1007/BF02478870

15. Zhu HD, Xie Q, Gong Y et al. Lymphoplasmacyterich meningioma: our experience with 19 cases and a systematic literature review. Int J Clin Exp Med. 2013;6(7): 504-515.

16. DiDomenico J, Ampie L, Choy W, et al. Sellar plasmacytomas masquerading as pituitary adenomas: A systematic review. J Clin Neurosci. 2018;50:20-23. https://doi.org/10.1016/j.jocn.2018.01.022

17. Mirra SS, Tindall SC, Check IJ, Brynes RK, Moore WW. Inflammatory meningeal masses of unexplained origin. An ultrastructural and immunological study. J Neuropathol Exp Neurol. 1983;42(4):453-468. https://doi.org/10.1097/00005072-198307000-00007

18. Bruno MC, Ginguené C, Santangelo $M$, et al. Lymphoplasmacyte rich meningioma. A case report and review of the literature. J Neurosurg Sci. 2004;48(3):117-124. PMID:15557881

19. Scheithauer, B. W.; Burger, P.C. In: Tumors of the central nervous system (AFIP Atlas of tumor pathology). Meningioma. Series 4, fascicle 7. Washington: ARP/ AFIP, 2007. p. 331-62.

20. Minniti G, Amichetti M, Enrici RM. Radiotherapy and radiosurgery for benign skull base meningiomas. Radiat Oncol. 2009;4:42. https://doi. org/10.1186/1748-717X-4-42 